\title{
Thin-walled profiles and their joint assembly units built with screws: numerical studies of load bearing capacity
}

\author{
Vadim Alpatov ${ }^{1, *}$, and Alexey Soloviev ${ }^{1}$ \\ ${ }^{1}$ Samara State Technical University, Academy of Architecture and Civil Engineering, \\ Molodogvardeyskaya St., 194, Samara, 443001, Russia
}

\begin{abstract}
There is a tendency to reduce weight of load-bearing metal structures being developed and successfully realized in modern building construction. This idea serves as a basis for a whole scientific direction, named Development and application of light steel thin-walled structures (LSTS). Among them, LTST built with pop-rivets and thread-cutting screws are most widespread due to their simplicity and relative cheapness This paper presents numerical studies of LSTS joint assembly units built with screws and their load bearing capacity. The peculiarity of these units consists in misalignment of joint elements. The calculation was performed in the SolidWorks Simulation System. The modeled node is a threedimensional assembly consisting of solid components. The results of the study are as follows: 1) thin-walled profiles have a significant sensitivity to eccentricity; 2) it is unacceptable to disregard eccentricities for thin-walled profiles and their joint connections; 3) eccentricities should be compensated by measures to improve reliability in joint connections design.
\end{abstract}

\section{Introduction}

There is a tendency to reduce weight of load-bearing metal structures being developed and successfully realized in modern building construction. This idea serves as a basis for a whole scientific direction, named Development and application of light steel thin-walled structures (LSTS). The use of LSTS in construction contributed to the development of machines and equipment which manufacture bent and weld-fabricated profiles of different sections in automatic and semi-automatic mode. The development of LSTS profile technology began in Canada and the United States in the early 1950s, and then spread to Canada, Europe, Asia, Australia and Russia [1]. The main normative and recommendation foreign documents on the design of buildings with the use of LSTS are mentioned in References [2, 3].

In Russia, the introduction of LSTS into the construction practice was rather slow beacuse of the absence of a clear regulatory framework. Until recently, Paper[4] served as the main guiding document on the use of LSTS. In 2016, Russia adopted Standard [5],

\footnotetext{
* Corresponding author: avu75@mail.ru
} 
which summarized requirements given in Papers [2-4]. But even before this standard appeared, LSTS already began to be used in low construction in Russia. As the questions of LSTS use were not examined well enough, their use brought about collapse of several buildings. Now, when Standard [5] has been introduced and there is more experience gained while designing and constructing buildings with frames of thin-walled profiles, reliability and safety of buildings should increase significantly. The process is also facilitated by numerous studies of thin-walled profiles, the ways they accommodate different types of loads [7-15] and research of their joint connections [9, 11-24]. The best results in designing of LSTS can be achieved by applying methods of optimal design of structures [25-27]. Analysis of accumulated statistics on accidents and building collapses with the use of LSTS makes it possible to point out one of the most frequently encountered errors - a mistake in the design and construction of nodes. Therefore, the study of the work of LSTS joint connections under load is an urgent task.

Joint connections of thin-walled profiles can be constructed with the use of welding, glue, bolts, thread-cutting screws and rivet methods [28]. Among them, LTST built with pop-rivets and thread-cutting screws are most widespread due to their simplicity and relative cheapness. This paper further presents numerical studies of LSTS joint assembly units built with screws and their load bearing capacity.

\section{Materials and methods}

The object of this study is the joint connection used in one of the collapsed buildings. LSTS profiles were used as pitched roof rafting structures of a three-floored building (see Figures 1,2 ). The roof was partially destroyed due to snow bags (see Figure 3). The inspection of the destroyed structures revealed a number of controversial technical solutions in the roof design. The main cause of the collapse was the loss of stability of compressed rods (see Figure 4). Another reason for the collapse of the roof was its joint connectionas destruction (see Figures 5, 6).

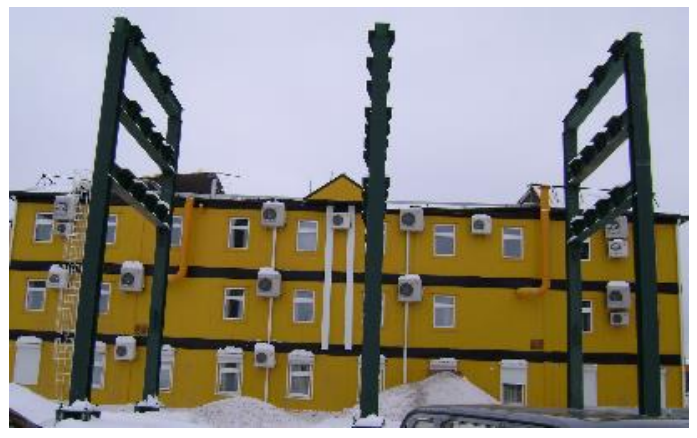

Fig. 1. Building with LSTS roof.

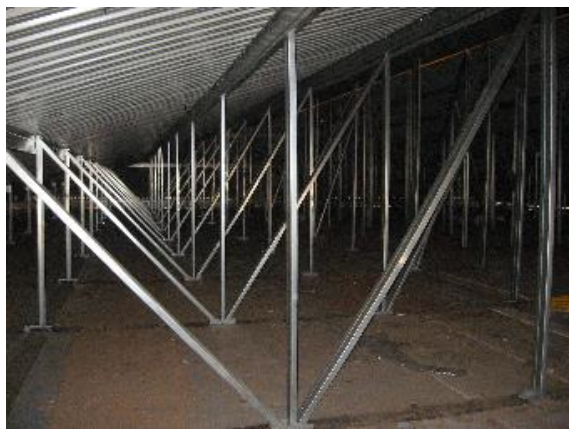

Fig. 2. Rafter system.

The peculiarity of joint connections in the construction of this roof was the disconnection of mating elements. The inter-crossing of the elements was done via side connection, causing the nodes to have eccentricities. These eccentricities were not taken into account when designing the roof. According to standard practice, it is reasonably required to take into account eccentricities in nodes while connecting thin-walled profiles. Thin-walled profiles have a significant sensitivity to eccentricity [22, 23]. 


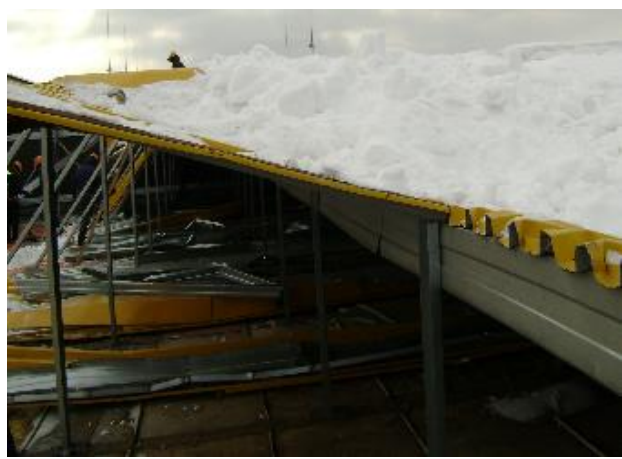

Fig. 3. Snow bag.

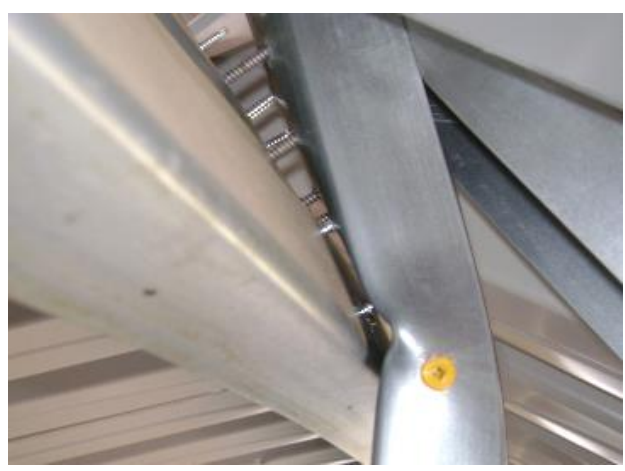

Fig. 5. Joint connection failure.

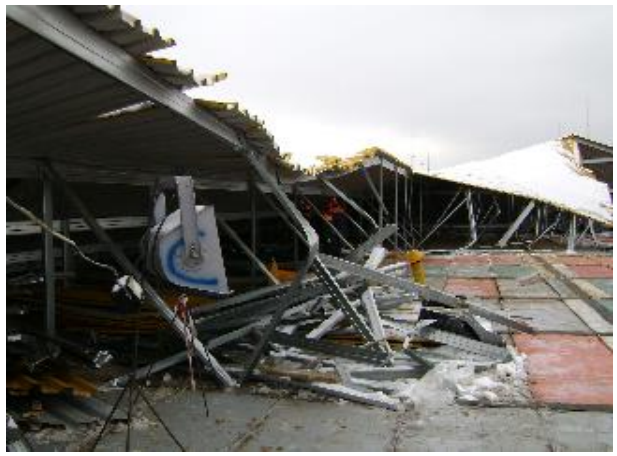

Fig. 4. Compressed rods buckling failure.

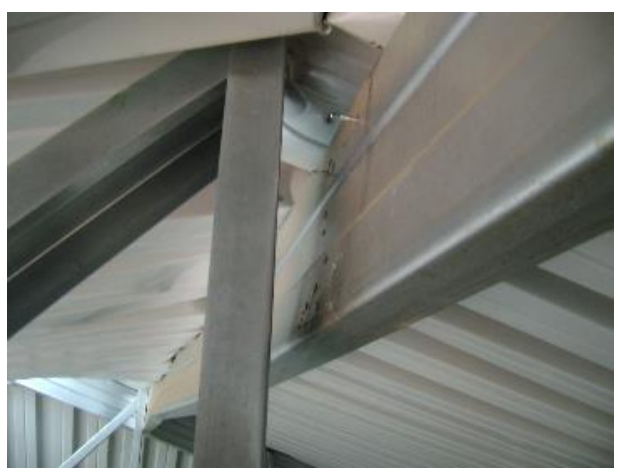

Fig. 6. Breaking and fracture of screws.

The authors took up studies of the stress-strain state of the node (Figure 7). For this purpose, they made a model of the node in a design complex SolidWorks (see Figure 8).

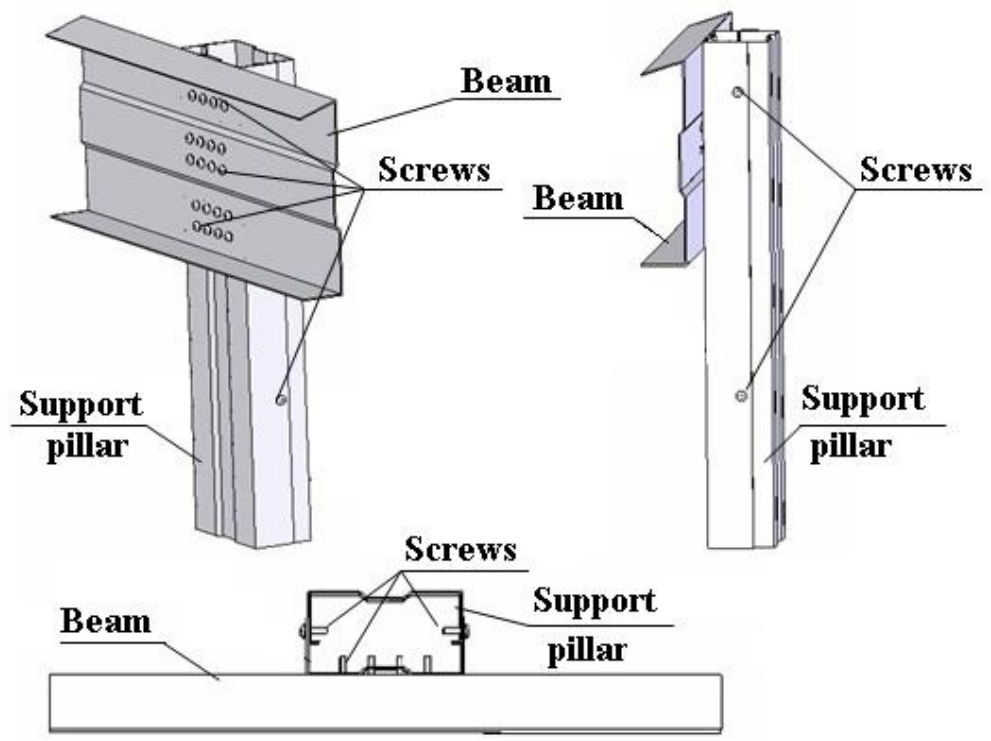

Fig. 7. Design of the investigated node. 


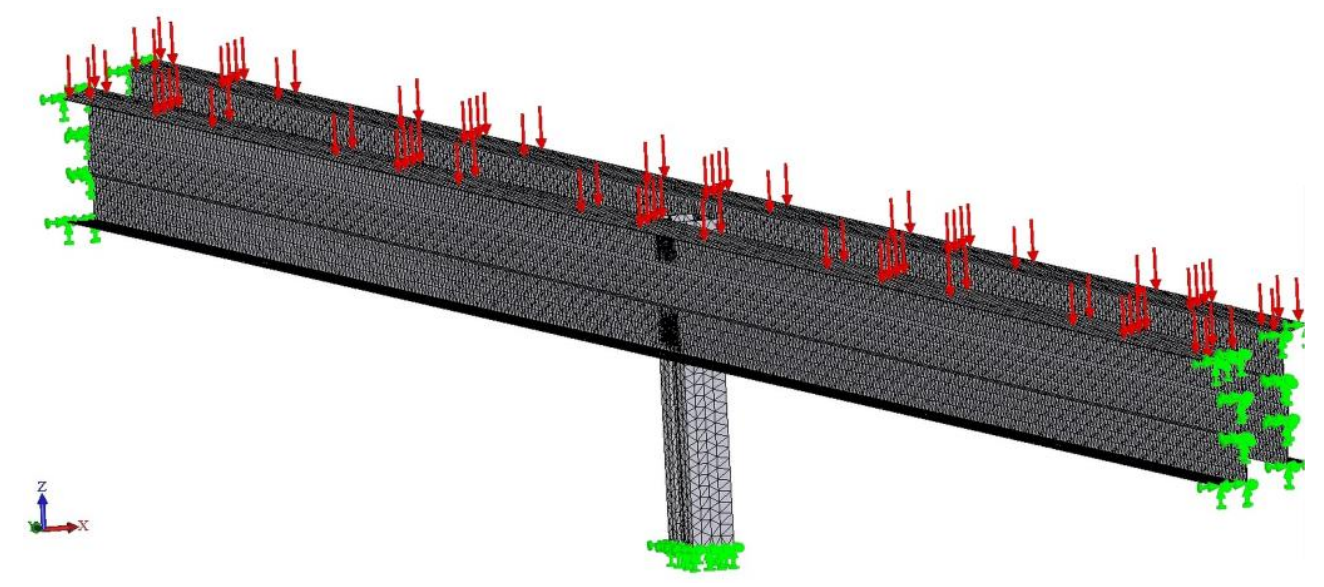

Fig. 8. Calculation model of the node.

The purpose of the study is to establish the strength and rigidity characteristics of the joint connection, as well as to determine its load bearing capacity.

The objectives of the study are as follows:

- to create a virtual model that takes into account peculiarities of the thin-walled profile geometry, the peculiarities of elements contact when connecting them with screws, the peculiarities of load transfer, the existence of eccentricity;

- to perform strain-stress state analysis in thin-walled elements and screws;

- to offer recommendations to ensure the reliability of the node.

The support pillar is made of a composite section of two profiles, joint into a case with thread-cutting screws. The longitudinal girder is a single profile attached to the support pillar with 24 screws (see Figures 7,8). The calculation was performed in the SolidWorks Simulation System. Boundary conditions emitted the following contacts:

- between the connecting elements - "without penetration", i.e. free separation and joint compression;

- between the screws and the connecting elements - "connected", that is joint deformation in any direction.

The stress-strain state in the elements of the model was determined from the evenly distributed load applied to the longitudinal girder. Calculations were performed several times. The load was increased with each subsequent calculation Then, deformations and stress levels in the elements of the calculation model were analyzed. The load was applied stepwise to achieve one of the following criteria:

- stresses corresponding to the limit of the material yield in thin-walled elements;

- stresses corresponding to the limit of the screws resistance to shear.

Stresses in the elements was calculated according to the Huber-Henckyvon Mises energy theory. These stresses values were compared with the metal yield strength of thin-walled elements. The stresses values for screws were determined by the Mor-Kulon criterion. These stresses were also compared with the limit of screws resistance to shear.

\section{Results}

The calculated stresses are shown in Figures 9-11. Stresses are shown separately for each element of the calculation model. As a result of investigations, the maximum permissible load on the node was calculated. Its value is about $40 \mathrm{kN}$. 


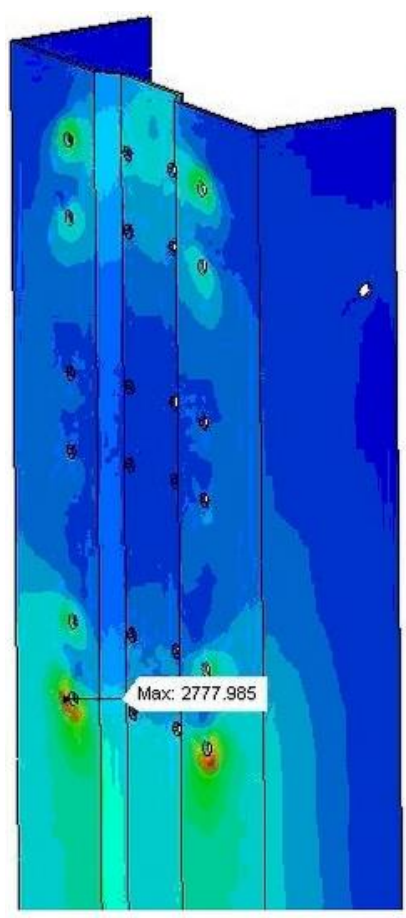

Fig. 9. Support pillar stresses

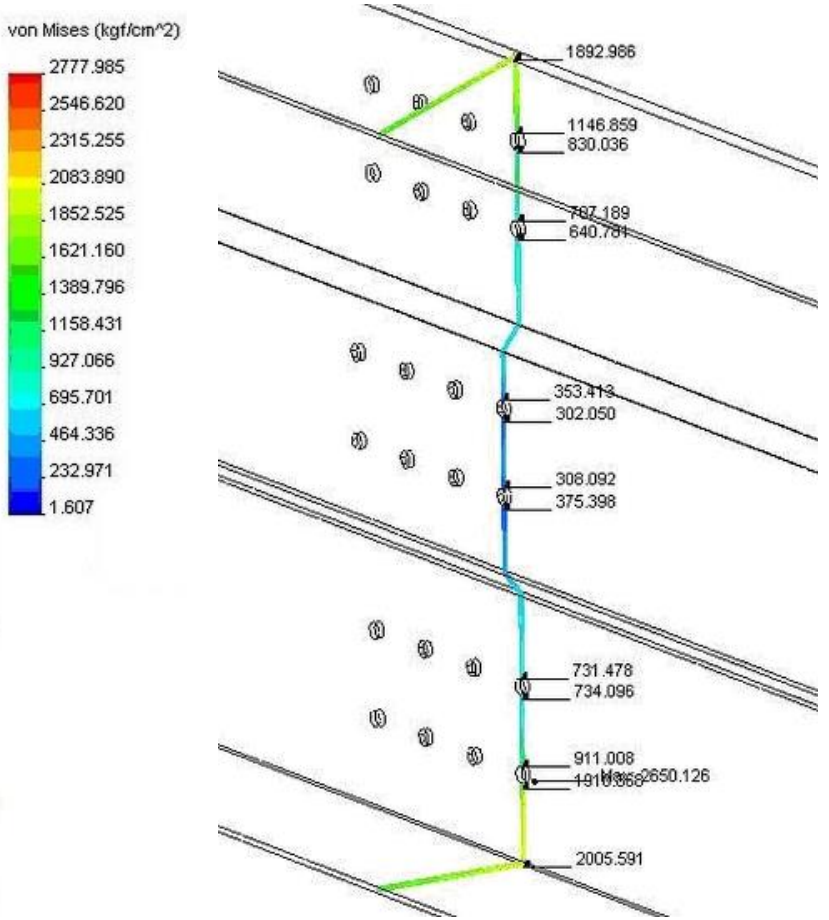

Fig. 10. Beam stresses
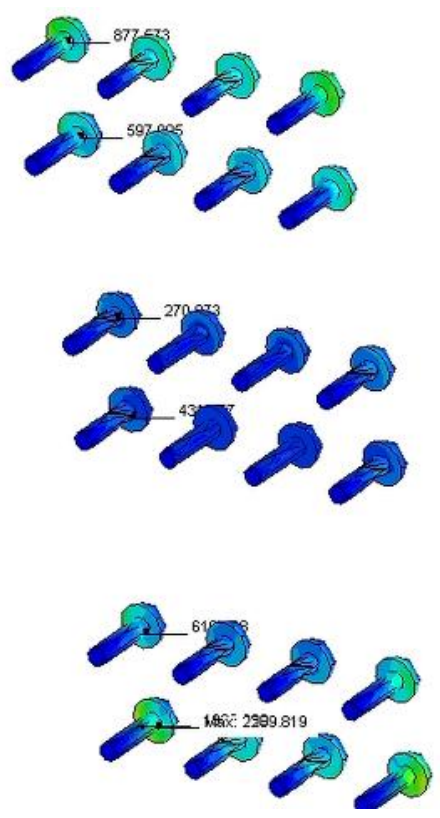

Fig. 11. Screws stresses.

\section{Conclusions}

1. The authors proved that the model destruction begins either when the yield limit of the connected elements or when the limit of the screws resistance to shear is achieved. 
2. The existence of eccentricities in the elements nodes leads to uneven loading of both connecting elements and connection screws.

3. Uneven loading of a node elements leads to greater stresses in the walls of connected elements. In these places, the stresses are significantly higher than the average stress in the section. The danger of the revealed situation is that traditionally in the design of such nodes the eccentricity is not taken into account, and the strength of the node is judged by the calculated average stresses.

4. Uneven loading of the node elements leads to uneven work of the connecting screws. This is the cause of their consistent destruction. In traditional design of such nodes it is considered that screws resist load evenly and are destroyed together.

5. In design and construction, the existence of eccentricities should be compensated by way of increasing constructive reliability of joint connections. There are the following ways to increase the constructive reliability of a node: installation of increased number of screws; distribution of local stresses to larger areas; installation of backing material and other means to tighten a wall of a profile at the place of fastening.

\section{References}

1. A. B. Chaganov, D. N. Rozhin, K. A. Matantsev, All-Russian annual scientific and technical conference "Society, science, innovations". Vyatka State University, 15731575 (2012)

2. T. Sputo, J. Turner, Bracing of cold-formed steel structures: A design guide (Prepared under contract to American Society of Civil Engineers-Structural Engineering Institute, ASCESEI, 2005)

3. EN 1993-1-3 Eurocode 3: Design of steel structures, Part 1-3: General rules, Supplementary rules for cold formed members and sheeting (European Committee for Standardisation, 2006)

4. Recommendations on designing, manufacturing and installation of load-bearing structure from steel bent profiles of increased rigidity (Melnikov Central Research and Design Institute of Steel Structures, 1999)

5. SP 260.1325800.2016. Steel thin constructions from bents galvanized profiles and corrugated sheets (Melnikov Central Research and Design Institute of Steel Structures, 2016)

6. I. S. Kholopov, A. V. Soloviev, Traditions and innovations in construction and architecture. Construction, 77-81 (2015)

7. A. S. Sinelnikov, A. V. Orlova, Vestnik MGSU 12, 41-54 (2013)

8. V. V. Yurchenko, Eng. and Constr. Mag. 8, 38-46 (2010)

9. A. S. Semenov, Thesis for PhD in Technical Sciences (Lipetsk, Lipetsk State Technical University, 2009)

10. D. S. Shatov, Master's thesis (St. Petersburg, Polytechnic University Publishing House, 2011)

11. V. A. Rybakov, Fundamentals of construction mechanics of light steel thin-walled structures (St. Petersburg, Polytechnic University Publishing House, 2011)

12. Yu. S. Kunin, A. I. Kolesob, et al, Vestnik MGSU 11, 74-81 (2012)

13. A. R. Tusnin, Ph.D. in Technical Sciences (Moscow, MGSU, 2003)

14. I. S. Kholopov, A. O. Lukin, et al., Building materials, equipment, technologies of XXI century 12 (155), 40-45 (2011) 
15. I. S. Kholopov, V. Yu. Alpatov, A. V. Atamanchuk, Building materials, equipment, technologies of XXI century 1, 66-68 (2008)

16. I. G. Katranov, Vestnik MGSU 2, 89-93 (2010)

17. I. G. Katranov, Assembly and special works in construction 5, 12-14 (2011)

18. I. G. Katranov, Thesis for $\mathrm{PhD}$ in Technical Sciences (Moscow, Melnikov Central Research and Design Institute of Steel Structures, 2011)

19. E. L. Atsrumyan, Assembly and special works in construction 3, 2-8 (2009)

20. I. L. Kuznetsov, R. R Ramazanov, KGASU News 3 (29), 51-55 (2014)

21. V. I. Tur, A. V. Tur, Fundamental research 9, 75-79 (2016)

22. B. D. Prosyanikov, Vestnik TGASU 2, 130-138 (2016)

23. I. S. Kholopov, V. Yu. Alpatov, A. V. Solovyev, Science and education in the XXI century. Collection of scientific papers based on materials of the International Scientific-Practical Conference: in 34 parts, 145-147 (2013)

24. I. S. Kholopov, V. Yu. Alpatov, et al., Collection of reports of the scientific and practical conference dedicated to the 100 anniversary of Professor E. I. Beleny "Calculation and design of metal structures", 236-241 (2013)

25. V. Yu. Alpatov, A. A. Sakharov, et al, MATEC Web Conf. 86, 02021 (2016)

26. V. Yu. Alpatov, A. A. Lukin, Procedia Engineering 111, 20-29 (2015)

27. I. S. Kholopov, M. I. Balzannikov, et al, Procedia Engineering 153, 277-282 (2016)

28. V. G. Kurazhova, T. V. Nazmeeva, Eng. and Constr. Mag. 3, 47-52 (2011) 